\title{
Biaya Perawatan Pesawat Udara dan Pedoman Perlakuan Akuntansi (Studi Pustaka)
}

\author{
Sudarno $^{(1)}$, Ryan Firdiansyah ${ }^{(2)}$ \\ ${ }^{1,2}$ Sekolah Tinggi Penerbangan AVIASI \\ sudarnobugis@gmail.com, ryan.firdiansyah.1979@gmail.com
}

\begin{abstract}
The purpose of this study is to inform literature in terms of aircraft maintenance on the basis of Law No. 1 of 2009 and IATA Guidelines regarding accounting calculations for airlines. In addition to the sources, the two rules above also use quantitative data on standard calculation of aircraft maintenance costs. Accounting and periodic reports, data on expenditures incurred by business enterprises are periodically collected and reported in the income statement, many types of expenses may require deferrals or accruals in certain circumstances, deferral costs, deferral costs are longterm prepayments with costs that must be paid for several years' operations are presented on the balance sheet in a section often referred to as deferral costs. Accrual, accruals are expenditures that gradually increase over time.

The International Air Transport Association is a flight accounting guideline that explains the maintenance for aircraft maintenance as follows; this is a generally accepted treatment for routine maintenance that is charged when it occurs, as well as most airlines burden annual aircraft costs as they occur on the grounds that these expenses are recurring and predictable and reasonable matching between income and expenditure, and accounting treatment for heavy maintenance and machine checks are not uniform. Aircraft generally adopt one of the following three methodologies when calculating these maintenance costs, costs incurred, provide accrual basis, delay and amortize. But if maintenance is delegated to an outsourcing company, the accounting treatment of maintenance costs does not adopt three methodologies but based on the recipient's invoice.
\end{abstract}

Keyword : Aircraft Maintenance, and Accounting Treatment 


\section{PENDAHULUAN}

Perawatan adalah semua kegiatan yang dilakukan untuk mempertahankan pesawat udara, komponen-komponen pesawat udara dan perlengkapannya dalam keadaan laik udara termasuk inspeksi, reparasi, servis, overhaul dan penggantian part. Untuk dapat melakukan perawatan dengan benar, maka setiap pesawat udara diharuskan memiliki Program Perawatan. terdapat 3 (tiga) pihak yang terlibat dalam penyusunan awal Program Perawatan, yaitu pabrikan pesawat udara, the Maintenance Review Board (MRB), dan the Industrial Steering Committee (ISC). Pabrikan berkewajiban membuat Policy and Procedures Handbook (PPH) yang berisi informasi lengkap dan jelas tentang proses penyusunan Program Perawatan Pesawat Awal. PPH kemudian diserahkan kepada ISC yang berkewenang untuk melakukan peninjauan terhadap PPH dan apabila telah memenuhi persyaratan maka ISC mengeluarkan persetujuan terhadap PPH (approval). Selanjutnya, ISC menyerahkan PPH kepada MRB untuk evaluasi dan analisis lebih lanjut.

Berdasarkan evaluasi dan analisis MRB dalam Warta Ardhia Jurnal Perhubungan Udara (Mora,Minda.2012), pabrikan membuat Maintenance Review Board Report (MRBR) dan Maintenance Planning Document (MPD). MRBR dan
MPD merupakan panduan bagi operator pesawat udara untuk melakukan perawatan pesawat udara dan membuat Program Perawatan pesawat udara sendiri. Namun, operator berkewajiban untuk memperbahatui Program Perawatannya apabila terdapat perubahan MRBR dan MPD dari pabrikan.

Amanat undang-undang bahwa setiap orang yang mengoperasikan pesawat udara wajib merawat pesawat udara, mesin pesawat udara, baling-baling pesawat terbang dan komponen lainnya secara berkelanjutan. Perawatan pesawat udara, mesin pesawat udara, baling-baling pesawat terbang dan komponen lainnya hanya dilakukan ; 1) perusahaan angkutan udara yang telah memiliki sertifikat operator pesawat udara; 2) badan hukum organisasi perawatan pesawat udara yang telah memiliki organisasi perawatan pesawat udara (approved maintenance organiztion); 3) personel ahli perawatan pesawat udara yang telah memiliki lisensi ahli pesawat udara (aircraft maintenance engineer licence)

Pengeluaran untuk perawatan pesawat udara adalah merupakan bagian dari biaya operasi semua perusahaan penerbangan, perusahaan angkutan udara niaga berjadwal maupun tidak berjadwal, baik pesawat udara tersebut adalah aktiva tetap milik sendiri maupun aktiva tetap sewa. Perusahaan penerbangan mempunyai 
keperluan perawatan pesawat udara tergantung dari umur pesawat udara, jenis pesawat udara yang dimiliki oleh masingmasing perusahaan penerbangan, serta struktur rute yang diterbangi.

Jenis - jenis perawatan berkala pesawat udara dapat dirincikan sebagai berikut:

INTERVAL MAINTENANCE OF

BOEING 737-300-400-500

\begin{tabular}{|c|c|c|}
\hline NO & $\begin{array}{c}\text { MAINTENANCE } \\
\text { ITEMS }\end{array}$ & INTERVAL \\
\hline $\mathbf{1}$ & PRE FLIGHT CHEK & $\begin{array}{l}\text { EVERY } \\
\text { CYCLE }\end{array}$ \\
\hline 2 & DAILY CHEK & 24 HOURS \\
\hline 3 & A-CHECK & $\begin{array}{l}200 \text { FLIGHT } \\
\text { HOURS }\end{array}$ \\
\hline 4 & C-CHECK & $\begin{array}{l}3000 \\
\text { FLIGHT } \\
\text { HOURS }\end{array}$ \\
\hline 5 & D-CHECK & $\begin{array}{l}22.000 \\
\text { FLIGHT } \\
\text { HOURS }\end{array}$ \\
\hline 6 & $\begin{array}{l}\text { LANDING } \quad \text { GEAR } \\
\text { EXCHANGE }\end{array}$ & $\begin{array}{l}22.000 \\
\text { FLIGHT } \\
\text { HOURS }\end{array}$ \\
\hline 7 & APU REPAIR & $\begin{array}{l}6.000 \\
\text { FLIGHT } \\
\text { HOURS }\end{array}$ \\
\hline 8 & BRAKE REPAIR & $\begin{array}{l}700 \text { FLIGHT } \\
\text { CYCLE }\end{array}$ \\
\hline 9 & $\begin{array}{l}\text { TYRE } \\
\text { REMOULD/REPLACE }\end{array}$ & $\begin{array}{l}\text { 200/800 } \\
\text { FLIGHT } \\
\text { CYCLE }\end{array}$ \\
\hline
\end{tabular}

\begin{tabular}{|l|l|l|}
\hline $\mathbf{1 0}$ & WHEEL REPAIR & $\begin{array}{l}1.600 \\
\text { FLIGHT } \\
\text { CYCLE }\end{array}$ \\
\hline
\end{tabular}

Data pendapatan usaha dan biaya yang terjadi dalam perusahaan secara berkala harus dipertemukan dan dilaporkan dalam laporan laba dan rugi(matching system); deferral adalah penundaan pengakuan biaya atas transaksi biaya yang telah dibayar; Prepaid expenses adalah biaya yang mempunyai manfaat dalam periode waktu jangka pendek yang digambarkan dalam neraca kelompok aktiva lancar dan menjadi biaya secara berkala bulan demi bulan; Deferred charges, pembayaran biaya yang telah dibayar yang mempunyai manfaat tahun jamak dan digambarkan dalam kelompok aktiva lain-lain (biaya ditangguhkan) menjadi biaya secara berkala bulan demi bulan maupun tahun demi tahun; Accrual adalah biaya dicadangkan secara berkala sehingga secara berangsurangsur bertambah. Accrued expenses, digambarkan dalam neraca kelompok hutang lancar manakala, penyelesaian dalam waktu kurang dari satu tahun, Other liabilities, biaya yang dicadangkan untuk tahun jamak dalam neraca dimasukan dalam kelompok kewajiban jangka panjang manakala penyelesaiannya lebih dari satu tahun, dan In Curred adalah pengakuan biaya dilaksanakan pada saat terjadi. 
Mengingat biaya perawatan pesawat udara dan mesin serta komponen pendukung lainnya yang besarannya melebihi 20 (dua puluh) persen dari total biaya perusahaan angkutan udara niaga baik berjadwal maupun tidak berjadwal maka dalam menentukan kebijaksanaan perlakuan akuntansi biaya perawatan pesawat udara harus memperhatikan beberapa aspek penting supaya kontribusi biaya dari tahun ke tahun sebanding dengan produksi jam terbang.

Ukuran besar kecilnya suatu perusahaan penerbangan sangat mempengaruhi perlakuan akuntansi biaya perawatan pesawat udara; Perusahaan penerbangan besar,sudah mapan dan mempunyai armada pesawat udara cukup banyak.Contoh; British Airways PLC 360 buah armada, Japan Airlines 170 buah armada,Qantas 111 buah armada, Singapore Airlines 93 buah Armada, dan Perusahaan penerbangan kecil, yang jumlah armada cukup kecil antara 10 buah-20 buah armada pesawat udara,

Kepemilikan Armada adalah status kepemilikan armada pesawat udara; Milik sendiri, armada pesawat udara yang dioperasikan adalah milik sendiri,dalam neraca dikelompokan dalam aktiva tetap, Sewa, armada yang dioperasikan adalah sewa, Finance lease, armada dalam sewa yang pada akhir periode sewa dapat dimiliki dalam neraca dikelompokan aktiva dalam sewa (aktiva lain-lain), dan Operating lease, dikelompokan dalam laporan laba dan rugi.

Direktorat yang berkepentingan dalam pelaksanaan perawatan pesawat udara adalah; Direktorat Marketing, menyiapkan struktur rute dengan cermat serta memperhatikan perencanaan perawatan pesawat udara sehingga pesawat udara selalu tersedia dalam mengisi struktur rute yang telah ditetapkan. Direktorat Teknik ; menyusun program dan pelaksanaan perawatan pesawat udara dengan mengacu kepada referensi yang berlaku baik dari pabrik pesawat udara, dan Civil Aviation and Safety Regulation, program perawatan pesawat udara harus disahkan oleh Menteri Perhubungan, menyiapkan suku cadang yang dibutuhkan sepanjang perawatan pesawat udara dilaksanakan sendiri.

Direktorat Keuangan, menyelesaikan pembayaran dan menentukan perlakuan akuntansi perawatan pesawat udara dengan memperhatikan kondisi perusahaan serta metode pembebanan biaya, setiap pilihan harus mempunyai dampak positif kepada keuangan perusahaan. PengeluaranPengeluaran yang tidak termasuk Biaya Perawatan; Betterment, yaitu pengeluaran untuk perbaikan aktiva tetap dengan tujuan untuk menambah nilai ataupun memperpanjang umur aktiva tetap tersebut, Replacement, yaitu penggantian komponen 
yang sudah rusak berat tidak dapat diperbaiki kembali walapun dapat diperbaiki akan mengeluarkan biaya yang besar (beyond economical repair) jadi lebih baik diganti dengan komponen yang baru, dan Addition,yaitu pengeluaran untuk menambah nilai aktiva umpama mengganti interior, exterior dan lain-lain .

\section{Pedoman Perlakuan Akuntansi}

Sebagai Acuan Untuk Perusahaan Angkutan Udara; Yang dibahas dalam perlakuan akuntansi perusahaan angkutan udara adalah perawatan pemeliharaan besar airframe pesawat udara (badan pesawat,sayap,ekor, rumah mesin dan roda) karena biaya yang harus dikeluarkan cukup besar seperti C check, D check dan mesin serta komponen pendukung pesawat udara, selanjutnya biaya tersebut didistribusikan dalam tahun jamak agar sebanding setiap tahun berdasarkan produksi jam terbang pesawat udara ,sedangkan perawatan kecil dan rutin langsung perlakukan dalam akuntansi kedalam biaya perawatan pesawat udara,namun dalam pelaksanaannya perlakuan akuntansi perawatan pesawat udara dilaksanakan sebagai berikut;

\section{Metodologi Penelitian}

Penelitian literatur ini merupakan kajian pustaka dari sudut pandang regulasi baik regulasi Nasional yaitu Civil Aviation Safety Regulation (CASR), dan UU No.1
Tahun 2009 dan regulasi Internasional seperti International Civil Aviation Organization (ICAO) Annex Standard and Recommended Practices, Federal Aviation Regulation (FAR) Amerika Serikat dan Joint Aviation Regulation (JAR) Uni Eropa dan lain-lain.

Expense as Incurred. beberapa perusahaan penerbangan sedang/ besar dan mapan mengakui semua biaya perawatan pesawat udara pada saat dilaksanakan, perawatan pesawat udara baik dilaksanakan sendiri maupun dilaksanakan oleh pihak ketiga.

Hal tersebut dilakukan mengingat bahwa perusahaan yang mempunyai armada banyak jumlah biaya dari tahun ke tahun akan selalu sebanding, namun dengan syarat bahwa perencanaan penggunaan armada dan perencanaan perawatan udara berkala direncanakan dengan teliti dan cermat serta selalu dimonitor dalam pelaksanaannya.

Untuk perusahaan penerbangan kecil memperlakuakan akuntansi biaya perawatan pesawat udara; Provide on the Accrual basis, beberapa perusahaan angkutan udara memperlakukan akuntansi biaya perawatan pesawat udara dan mesin serta komponen pesawat udara berdasarkan perkiraan biaya yang akan timbul pada saat perawatan pesawat udara besar dilaksanakan, mesin pesawat udara cadangan dilaksanakan 
menggunakan dasar jam terbang, yaitu perkiraan biaya dibagi umur mesin diantara selang waktu overhaul (time between overhaul) dikalikan produksi jam terbang selama setahun, perawatan pesawat udara khususnya $\mathrm{C}$ check dan $\mathrm{D}$ check dengan memperkirakan jumlah biaya yang akan timbul perawatan tersebut dibagi dengan umur airframe diantara selang waktu overhaul untuk pesawat udara (tbo) contoh B737-500 C check 3.000 jam terbang sedangkan untuk D check 22.000 jam terbang, selanjutnya dikalikan dengan produksi jam terbang selama setahun, sehingga biaya perawatan pesawat udara setiap tahun proposional dengan produksi jam terbang.

Defer and amortise Sebagian kecil perusahaan angkutan udara membukukan biaya perawatan pesawat udara baik airframe maupun mesin serta komponen pendukung lainnya dengan membukukan nya sebagai defer adapun perlakuan akuntansi biaya perawatan pesawat udara dengan cara amortisasi sebesar jumlah biaya yang sudah dibukukan sebagai defer dibagi dengan jam produksi selang waktu overhaul (tbo) dikalikan produksi jam terbang per tahun .

Outsourcing adalah pendelegasian fungsi usaha kepada perusahaan lain baik keseluruhan maupun sebagian dan bersamasama melakukan kontrol administrasi maupun operasional. Namun mengingat pada dewasa ini perusahaan angkutan udara niaga berjadwal mengkonsentrasikan diri kepada usaha utamanya seperti perencanaan strategis, penjualan tiket, pengangkutan penumpang dan pelayanan penumpang maka perawatan pesawat udara didelegasikan kepada pihak ketiga yang memiliki Approved maintenance organization (AMO). Metode outsourcing ini merupakan inovasi baru yang sudah berjalan kurang lebih selama sepuluh tahun.

MAINTENANCE OUTSOURCING

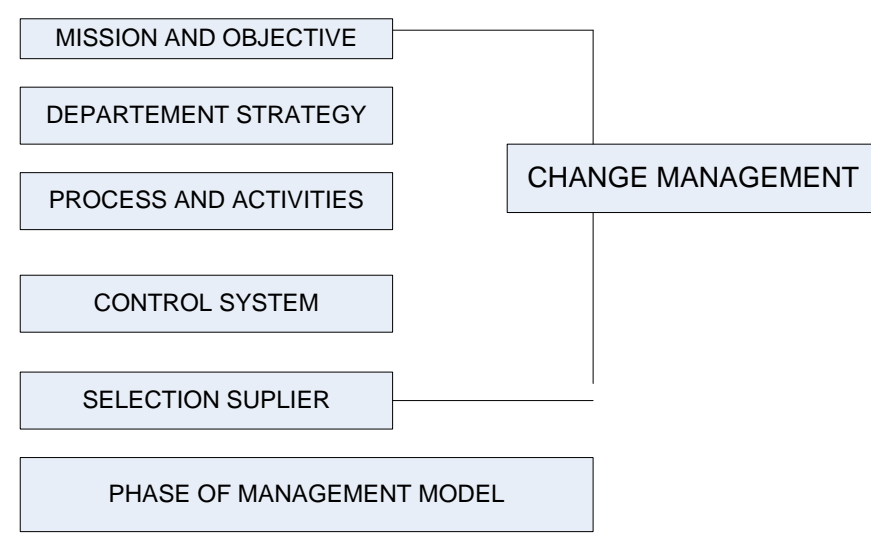

\section{PEMBAHASAN}

Berdasarkan Civil Aviation Safety Regulation (CASR) part 43 tentang Maintenance, Preventive Maintenance, Rebuilding and Alteration pengertian maintenance (perawatan) adalah semua kegiatan yang dilakukan untuk mempertahankan pesawat udara, komponen-komponen pesawat udara dan perlengkapannya dalam keadaan laik 
udara (airworthy) termasuk inspeksi, reparasi, service, overhaul dan penggantian part. Perawatan pesawat udara,bertujuan untuk menjaga kelaikan terbang pesawat yang bersangkutan. Proses penjagaan kelaikan dimulai sejak pesawat udara masih dalam tahap desain, tahap pengembangan dan sertifikasi pesawat baru dan berlanjut terus pada saat pesawat udara dioperasikan.

Awal mula konsep perawatan pesawat udara (juga industri lainnya) dikenal dengan istilah 'fixed it when broke', yaitu perbaikan dilakukan apabila terjadi kerusakan. Tapi kemudian, mulai banyak kebutuhan ketika faktor keselamatan mulai diperhitungkan, sehingga muncullah preventive maintenance (perawatan pencegahan), dengan sistem overhaul yang dikenal dengan istilah Hard Time (HD). Sistem Hard Time mengacu kepada prinsip umur komponen/ part. Apabila komponen/ part pesawat udara sudah mencapai umur yang ditentukan, maka komponen/ part harus diganti walaupun komponen/ part tersebut masih dalam kondisi yang bagus. Sistem Hard Time ini sangat merugikan maskapai penerbangan, karena mengeluarkan biaya yang besar untuk perawatan.

Maka sebelum perusahaan angkutan udara niaga berjadwal memilih perusahaan untuk melaksanakan perawatan pesawat udara beserta komponen pendukung lainnya perlu kajian-kajian sebagai berikut; kemampuan mitra kerja yang akan dipilih dalam melaksanakan perawatan pesawat udara, menyeleksi mitra kerja bukan hanya mengenai harga yang bersaing namun faktor-faktor lain yang menyangkut pengalaman, reputasi, kestabilan keuangan serta peralatan dan teknologi yang tidak kalah penting sebagai bahan pertimbangan, bila mungkin dengan melakukan uji coba perawatan pesawat udara bila memuaskan dapat dilanjutkan dengan membuat perjanjian kerja, karyawan harus diberitahukan mengenai pengalihkan perkerjaan yang bukan usaha utamanya kepada pihak ketiga yang mempunyai kemampuan.

Perawatan pesawat udara selalu dalam pengawasan badan pemerintah yang berwenang, sehingga perusahaan tidak khawatir pekerjaan perawatan pesawat udara dilaksanakan oleh perusahaan lain, Sebagai dasar perlindungan hukum kedua belah pihak baik bagi perusahaan angkutan udara niaga berjadwal maupun mitra kerja perawatan pesawat udara maka dibuatkan surat perjanjian perawatan pesawat udara dan komponen pendukungnya sebagai pengganti surat perintah kerja (work order) ; perusahaan angkutan udara niaga berjadwal menyerahkan perawatan pesawat udara dan mesin pesawat udara serta komponen pendukung lainnya untuk seluruh armada 
yang dimiliki kepada perusahaan perawatan pesawat udara untuk dilakukan perawatan.

Perusahaan perawatan pesawat udara yang memiliki AMO menerima pesawat udara , dan komponen pendukungnya untuk dilakukan perawatan, jangka waktu, mengingat rentang waktu perawatan berkala dari mulai nol jam terbang sampai dilaksanakan D check memerlukan waktu yang panjang sekitar lima sampai tujuh tahun serta untuk menghindari kerugian dari kedua belah pihak maka jangka waktu perjanjian dibuat untuk waktu yang panjang (long life agreement).

Klasifikasi Perawatan Pesawat Udara Setiap pesawat udara selama beroperasi pasti mempunyai jadwal untuk perawatan. Perawatan ini harus dilakukan karena setiap komponen mempunyai batas usia tertentu sehingga komponen tersebut harus diganti. Selain itu, komponen juga harus diperbaiki bila ditemukan telah mengalami kerusakan. Secara garis besar, program perawatan dapat dibagi menjadi dua kelompok besar, yaitu perawatan preventif dan korektif.

Perawatan preventif adalah perawatan yang mencegah terjadinya kegagalan kembali ke kondisi awal. Perawatan preventif dapat dibagi menjadi 2 jenis yaitu Perawatan periodik atau hard time, merupakan perawatan yang dilakukan berdasarkan batas waktu dari umur maksimum suatu komponen pesawat.
Dengan kata lain, perawatan ini merupakan perawatan pencegahan dengan cara mengganti komponen pesawat meskipun komponen tersebut belum mengalami kerusakan; Perawatan on-condition, merupakan perawatan yang memerlukan inspeksi untuk menentukan kondisi suatu komponen pesawat. Setelah itu ditentukan tindakan selanjutnya berdasarkan hasil inspeksi tersebut. Bila ada gejala kerusakan, komponen tersebut dapat diganti bila alasanalasan teknik dan ekonominya memenuhi.

Perawatan pesawat udara biasanya dikelompokkan berdasarkan interval yang sepadan dalam paket-paket kerja atau disebut dengan clustering. Hal ini dilakukan agar tugas perawatan lebih mudah, efektif dan efisien. Interval yang dijadikan pedoman untuk melaksanakan paket-paket tersebut adalah sebagai berikut: Flight hours, merupakan interval inspeksi yang didasarkan pada jumlah jam operasional suatu pesawat udara; Flight cycle, merupakan interval inspeksi yang didasarkan pada jumlah lepas landas dan pendaratan yang dilakukan pesawat udara. Satu kali lepas landas dan pendaratan dihitung satu cycle; Calendar time, merupakan interval inspeksi yang dilakukan sesuai dengan jadwal tertentu.

Dari jumlah tugas perawatan atau inspeksi yang dilaksanakan, perawatan 
dapat dibagi dalam minor maintenance seperti transit check, before departure check, daily check, weekly check dan heavy maintenance seperti A-Check, BCheck, C-Check dan D-Check; Minor maintenance, terdiri dari; Transit check. Inspeksi ini harus dilaksanakan setiap kali setelah melakukan penerbangan saat transit di station mana pun. Operator biasanya memeriksa pesawat untuk memastikan bahwa pada pesawat tidak terdapat satu pun kerusakan struktur, semua sistem berfungsi dengan sebagaimana mestinya, dan servis yang diharuskan telah dilakukan; Before Departure Check; Inspeksi ini harus dilakukan sedekat mungkin sebelum tiap kali pesawat berangkat beroperasi, maksimal dua jam sebelumnya; Daily Check (Overnight Check);

Pemeriksaan ini harus dilakukan satu kali dalam jangka waktu 24 jam setelah daily check sebelumnya dilakukan. Setiap hari pesawat telah diprediksi akan ground stop minimal selama empat jam. Inspeksi ini mencakup pemeriksaan komponen, pemeriksaan keliling pesawat secara visual untuk mendeteksi ada atau tidaknya ketidaksesuaian, melakukan pengamanan lebih lanjut, dan pemeriksaan sistem operasional; Weekly check. Pemeriksaan ini harus telah dilakukan dalam tujuh hari penanggalan. Termasuk dalam inspeksi ini adalah before departure check; Heavy maintenance, terdiri dari: A-Check dilakukan kira- kira setiap satu bulan. Pemeriksaan ini biasanya dilakukan hingga 10 jam. Pemeriksaan ini bervariasi, bergantung pada tipe pesawat, jumlah siklus (lepas landas dan pendaratan dianggap sebagai siklus pesawat, atau jam terbang sejak pemeriksaan terakhir). Perawatan pesawat jenis ini hanya melakukan pemeriksaan pada pesawat untuk memastikan kelaikan mesin, sistemsistem, komponen-komponen, dan struktur pesawat untuk beroperasi. Untuk Boeing 737: Classic, A-check dilakukan setelah 300 jam terbang, Airbus A340 setelah 450 jam terbang, Boeing 747-200 setelah 650 jam; B-Check - bergantung pada masing-masing jenis pesawat.

Pemeriksaan berkisar antara 9 hingga 28 jam ground time dan biasanya dilakukan kira-kira setiap lima bulan. Perawatan pesawat dalam skala kecil ini hanya meliputi proses pembersihan, pelumasan, penggantian ban apabila sudah aus, penggantian baterai, dan inspeksi struktur bagian dalam; C-Check sebuah pesawat harus melakukan $C$-Check setelah 15-18 bulan. Bergantung pada tipe pesawat, pemeriksaan ini bisa memakan waktu 10 hari. Perawatan pesawat tipe ini merupakan inspeksi komprehensif termasuk bagian-bagian yang 
tersembunyi, sehingga kerusakan dan keretakan di bagian dalam dapat ditemukan. Untuk Boeing 737-300 dan 737-500, inspeksi ini dilakukan setiap $4.000 \mathrm{FH}$.

Untuk Boeing 737-400 dilakukan setiap 4.500 FH. Sedangkan untuk Boeing 747-400 dilakukan setiap 6.400 FH dan Airbus A-330-341 dilakukan setiap 21 bulan; D-Check - inspeksi ini biasa disebut overhaul. Pemeriksaan jenis ini adalah perawatan yang paling detail. Pesawat Boeing 737-300, 737-400 dan 737-500 inspeksi ini dilakukan setiap 24.000 FH. Sedangkan untuk Boeing 747400 dilakukan setiap 28.000 FH dan untuk Airbus A-330-341 dilakukan setiap 6 tahun. Pada pengecekan jenis ini pesawat diinspeksi secara keseluruhan, biasanya memakan waktu 1 bulan.

\section{Keuntungan bagi Perusahaan} Angkutan Udara ; dapat berkonsentrasi kepada usaha utamanya, dapat memilih mitra kerja yang berkualitas tinggi, akan memberikan keuntungan dari biaya perawatan pesawat udara yang efisien, memudahkan dalam penyusunan anggaran perawatan pesawat udara serta anggaran kas, tidak disibukan mengurus karyawan teknik yang cukup besar, dan sebagian dapat dipindahkan ke perusahaan perawatan pesawat udara dalam negeri yang melaksanakan perawatan pesawat udara perusahaan dan tidak disibukan dengan pembelian suku cadang dan penyimpanan persediaan suku cadang.

Mengingat bahwa dalam kenyataan yang ada berdasarkan perjanjian perawatan pesawat udara penagihan biaya perawatan pesawat udara kepada perusahaan angkutan udara niaga berjadwal secara proposional berdasarkan jumlah produksi jam terbang bulanan dikalikan tarif yang ditentukan dimuka (termasuk didalamnya jumlah tenaga kerja dan waktu serta suku cadang dibutuhkan), dengan memperhatikan regulasi perpajakan yang berlaku.

Maka perlakukan akuntansi biaya perawatan pesawat udara tidak lagi mengacu berdasarkan terjadinya perawatan pesawat udara,cadangan maupun amortisasi yang berlaku umum maupun tiga metodologi yang diarahkan oleh International Air Transport Association (IATA) namun berdasarkan faktur (invoice) yang diterima dari perusahaan perawatan pesawat udara walaupun perawatan pesawat udara mungkin baru sebagian dilaksanakan. Dengan demikian perlakuan biaya perawatan pesawat udara berdasarkan faktur (invoice) yang diterima dari perusahaan perawatan pesawat udara.

\section{KESIMPULAN}

Perawatan pesawat diperlukan dan harus rutin dilaksanakan, dengan menggunakan 
inovasi baru dari perusahaan perawatan pesawat udara yang merupakan daya tarik tersendiri bagi perusahaan angkutan udara niaga berjadwal yang dalam melaksanakan perawatan pesawat udara mulai dari A check sampai dengan $\mathrm{D}$ check, mesin pesawat udara dan komponen pendukungnya diserahkan kepada perusahaan lain (outsourcing) Hal tersebut dipilih karena biaya yang dibukukan proposional dengan produksi jam terbang dikalikan dengan tarif yang telah ditentukan dimuka berdasarkan kesepakatan bersama dan sudah barang tentu dengan harga yang bersaing, yang secara ekonomi lebih menguntungkan.

Contoh perhitungan dalam perawatan pesawat di bagian opeasr dan produksi rata-rata per hari per pesawat udara masing-masing 10 jam dengan tarif per jam yang telah disepakati bersama sebesar USD 895.00 Sedangkan jumlah armada yang di operasikan sebanyak 10 pesawat udara maka jumlah tagihan dalam satu bulan $=30$ hari $\mathrm{x}$ 10 jam x 10 pesawat udara $\times$ USD895.00 = USD2.685.000,-.

Tegasnya jumlah tagihan sangat tergantung dengan jumlah produksi jam terbang hal ini sangat membantu dalam penggaran kas keluar. Sedangkan perlakuan akuntansi biaya perawatan pesawat udara dilaksanakan pada bulan produksi sesuai yang ditagih oleh perusahaan perawatan pesawat udara ,tidak lagi bertumpu kepada tiga metodologi (expense as incurred,provide on the accrual basis dan defer and amortise) yang dijelaskan diatas. Dengan demikian bahwa inovasi bisnis dan akuntansi akan selalu berkejaran saling mendahului.

\section{DAFTAR PUSTAKA}

Adam Durschlag, Q Finance, The Ultimate Resource No 1, bloomsbury, Qatar Fundation,Publishing Second Edition 2010 .

Asp B. "Maintenance Program Development and the Definition of the Maintenance Program Process".2008.

Civil Aviation Safety Regulation (CASR) part 43 tentang Maintenance, Preventive Maintenance, Rebuilding and Alteration.

Civil Aviation Publication CAP 25 tentang Maintenance Program.

CAD 452. - Aircraft Maintenance Schedule and Program: Information and Guidancell. Civil Aviation Department Hongkong China. 2012

International Air Transport Association - Maintenance Costs for Aging Aircraft ed $1^{\text {th }}-2018$.

Mora Minda, Warta Ardhia Jurnal Perhubungan Udara Vol 38, No 4. 2012.

Niswonger/Fess. 1980. Accounting Principles. South-Western; 13th edition.

Republik Indonesia. UndangUndang No.1. Tahun 2009 tentang Penerbangan. 
Takele T. "Maintenance Program

Development and Import/Export of Aircrat

in USA". 2009. 